\section{A CASE OF TETANUS SUCCESSFULLY TREATED WITH ANTITOXIN.}

BY W. TYRRELL BROOKS, M.A. OXON., M.B. LOND., SENIOR PHYSICIAN TO THE RADCLIFFE INFIRMARY, AND LITCHFIELD LECTURER IN MEDICINE IN THE

$$
\text { UNIVERSITY OF OXFORD. }
$$

A LADY, aged twenty-four years, whilst away for a holiday met with a bicycle accident on Sept. 9th, 1897, which caused a contused wound on the left thamb, the wound containing a quantity of dirt from the road on which she fell. The wound was treated with bread poultices and then dressed with iodoform and did not cause any uneasiness to the patient. On her return to Oxford there was a definite history of chill from exposure and on the tenth day after the accident she first noticed stiffness of the muscles of the jaw. On the following day I saw her and examined the wound which I found covered with a crust of iodoform and dried pus beneath which was a pale, unhealthy granulating surface. She complained of stiffness in the masseters and difficulty in mastication. The lower jaw could be opened voluntarily to the extent of an inch but not without difficulty. The wound was at once treated with hot boracic fomentations. These were kept up for a week or ten days and I may here add that no further trouble was caused by the wound, which healed some days before the attack of tetanus terminated. The patient was ordered a fluid diet, five grains of calomel, and a chloral and bromide draught. On the following day it was evident that tetanus had developed, the masseters were firmly contracted and there was spasm of the retractor muscles of the head, whilst on getting the patient out of bed general muscular spasm followed. Treatment with antitoxin was at once commenced, 10 c.c. of the dried serum (prepared by the Pasteur Institute by a modification of Roux's method) being injected at 12 A.M., a second similar injection being given at 6 P.M. The muscles of deglutition were not affected and the patient took fluid nourishment freely. On the 22nd there were frequent spasms of the muscles of the upper trank and arms which or me on at intervals of an hour and which when severe spread to the legs. In the intervals between the spasms there was stiffness in the muscles of the left scapula and the patient lay with the head rigidly retracted. The facial muscles were involved in the spasm, causing a marked alteration in the patient's expression. Swallowing was difficult during the day owing to spasm of the pharyngeal muscles. The patient sweated profusely throughout the day and was in great pain. Two injections (each consisting of 10 c.c. of antitoxin) were given during the day. On the 23rd the spasms were more frequent and general, opisthotonos occurring during the more severe spasms. Two injections of antitoxin were given. On the 24th and 25th the symptoms remained unaltered except that the spasms were more frequent. Two injections of antitoxin were given each day. On the 26th the only alteration in condition was the presence of risus sardonicus, which appeared with each attack of general spasm, passing off in the interval. There was also constant numbness of both legs, but most marked in the right. Two injections of antitoxin were given during the day. On the 27 th the condition remained unaltered. Two injections of antitoxin were giving during the day. On the 28th the patient appeared worse, the general spasms occurring with great frequency and the pain from them not being controllable by morphia. Menstruation appeared on this day. On the 29 th there was slight improvement, the spasms lessening in frequency, and trom this date to Oct. 1st, when the antitoxin treatment was discontinued, there was gradual amelioration in the patient's condition. In all the patient had seventeen injections of antitoxin, each consisting of $10 \mathrm{c} \mathrm{c}$. After Oct. 18t the patient's history was uneventful. There were for several days attacks of muscular spasm which were controlled by morphia. The patient gradually began to recover voluntary movement in the muscles and the masseter spasm relaxed sufficiently to allow finely minced foods to ba taken. The only new symptom present during early convalescance was diplopia, which continued for four days. Tendon reflexes were greatly exaggerated and ankle clonus was present on both sides. Ankle clonus persisted until Oct. 17th. On the 20th the patient had sufficient control over the legs to allow her to walk a few steps. From this time there has been steady improvement and at the present date (Dec. 17th, 1897) the patient can walk a couple of miles at a stretch and considers herself quite in her normal health. I may add that in addition to the injections of antitoxin morphia was used freely during the acute part of the illness with large doses of chloral bydrate and bromide of potassium at night.

Oxford.

\section{Clinital Antes:}

\section{MEDICAL, SURGICAL, OBSTETRICAL, AND} THERAPEUTICAL.

\section{A CASE OF RAPID DEVELOPMENT OF SYMPTOMS OF} BELLADONNA POISONING FROM USE OF SULPHATE OF ATROPINE GYE DROPS.

By WoRsley J. Harris, L.R.C.P. LoNd., M.R.C.S. Eng.

I WAS called hurriedly one Monday afternoon to see a woman, aged thirty years, who had been taken suddenly ill with giddiness and fainting attacks accompanied with peculiar oppressed feelings at the heart. I found the patient lying on the bed in a flashed and excited state with cold extremities, quick pulse, and feeling shivery, sick, and giddy. She had dryness of the tongue, lips, mouth, and throat and a great craving for drink. The pupils were widely dilated and the urine had been very scanty though she felt a constant desire to micturate. She informed me that she had been perfectly well the week before until on the Saturday (the day before she was taken ill) she went to an oculist about her eyes. The oculist being away his colleague had prescribed for her. She was given for the eyes atropine drops (four grains of sulphate of atropine to one ounce of distilled water), two drops every four hours, and internally she was ordered biniodide of mercury (two grains, make fifty pilules, three to be taken every four hours). She first used the drops and the pilules that night and continued to do so throughout Sunday. She began to feel slightly all the above symptoms on Sunday evening, especially the oppression at the heart and giddiness, which became particularly bad after taking food. Diagnosing the case as one of acute belladonna poisoning I caused the drops to be discontinued (as well as the pilules) for the time being as the pupils were widely dilated. She was ordered to rest quietly in bed and to have plenty of warm and good liquid nourishment frequently and in small quantities with a little alcohol, and a mixture was prescribed containing digitalis, nux vomica, and aromatic spirit of ammonia. This steadied the heart and increased the flow of urine and she was much better on the next day but complained of nausea. For the nausea she had a mixture of liquor bismuthi, solution of bimeconate of morphine, dilute hydrocyanic acid, \&c., with which she was pleased, as one dose she averred took away all sickness. On the following day she was well enough to go to see the oculist and told him how ill she had been. He ordered the drops once a day and only three pilules a day.

I relate this case thinking it may be of some little intere $3 t$ in showing how rapidly such symptoms may develop in some people from a very slight cause. The patient was suffering from syphilitic iritis. For this she had the atropine drops and the mercury iodide; but either from an inherent susceptibility to the drug or from her being more susceptible from weakness due to the syphilitic poison her system could not withstand even atropine drops in ordinary doses, but only in the very weakest strength. I can only call to remembrance seeing one other case with symptoms of decided belladonna poisoning from the use of atropine drops, but that was in a child who had used weaker drops for some two months and more regularly every day. Has.ings. 